\title{
Research agenda for autologous blood transfusion
}

It is understandable why autologous blood is perceived to be safer for the patient than homologous blood. However, in depth examination of the factors involved from selection to collection, storage, and issue, reveals that some of the recognised hazards of blood transfusion (eg, Yersinia enterocolitica septicaemia) are inherent to both homologous as well as autologous blood transfusion. ${ }^{12}$ Indeed some risks are peculiar only to recipients of autologous blood transfusion because they are related to the process of donating blood, particularly if the age of patients undergoing the operations (eg, hip replacement) targeted for autologous blood transfusion is taken into consideration. Myocardial infarction or angina pectoris occurred in four and cerebrovascular accidents in three of a total of 320 orthopaedic patients following pre-operative autologous deposits (PAD), with or without erythropoietin supplement, reported in two separate studies. ${ }^{34}$ Regardless of erythropoietin treatment, $10 \%$ of all patients undergoing PAD developed other significant side-effects. Paradoxically, the anticipated benefit will not be experienced by such elderly patients because their life expectancy is shorter than the latency period preceding clinical manifestation of the presumed risks.

The debate is often deflected to one about cost considerations even before the medical risks and benefits of autologous versus homologous blood is properly assessed by documented facts and figures. Clinical research in this area is hampered by naivety of design, which often introduces bias as the major factor influencing results and outcome. Confounding factors render both clinical research findings as well as economic assessment based on clinical research untenable because of flawed assumptions.

Economic assessments to date have conceded that the direct cost of autologous blood transfusion is higher than that of homologous blood. ${ }^{5}$ However, isolated reports argue that the use of autologous blood transfusion can be justified on economic grounds because it is associated with reduced postoperative infection rates and shorter hospital stays than allogenic transfusion. ${ }^{6}$ It is presumed that homologous blood suppresses the immune system and in turn leads to infectious and other complications associated with impaired immune surveillance such as recurrence of malignant tumours.

The benefits alleged to be associated with PAD have not been substantiated by sufficiently large randomised controlled trials. The 'evidence' for these benefits merely indicate that patients who were fit enough to donate blood for themselves before their operations had less postoperative infections and shorter hospital stays than patients who were less fit. ${ }^{7}$ The design of autologous versus homologous blood transfusion studies hitherto is biased in favour of better results in fit patients (able to pre-deposit blood or needed no blood transfusion). The endpoint (length of hospital stay) is so subjective that it can be easily shortened or prolonged (as the case may be) to suit a Senior Registrar anxious to have an impressive $\mathrm{CV}$ in order to secure a Consultant post! Of course, negative findings are less likely to be published.

More recent studies are sophisticated enough to control for some confounding factors and their conclusions are different. By incorporating multivariate analyses, no difference was shown in the recurrence rate for malignant tumours, ${ }^{8}$ emergence of second malignancy, ${ }^{9}$ or overall survival between recipients of autologous or homologous blood transfusion. ${ }^{10}{ }^{11}$ Furthermore, no significant difference in immune function was detected by a wide range of tests between recipients of autologous and homologous blood. ${ }^{12} 13$

The controversy is still unresolved, with claims and counterclaims. A convincing difference in outcome (postoperative infection rate or length of hospital stay) in recipients of autologous versus homologous blood transfusion may be demonstrated if:

- patients eligible to pre-deposit blood only are enrolled in a double-blind randomised controlled trial

- since donating blood can arguably have a negative or positive immunomodulatory effect, and in view of the double-blind nature of the trial, patients randomised to either arm of the study (autologous or homologous blood transfusion) should predeposit enough units for their operative and postoperative blood transfusion requirements. The decision to transfuse or not must be taken by clinicians unconnected to the trial, and neither treating clinicians (observing and recording outcome) nor patients must be aware of the nature of transfused blood

- in either study arm, patients must be excluded from the analysis if they require more units than their predeposit. A trial incorporating these pre-requisites to assess the difference in outcome between patients in the two arms should yield invaluable information to elevate the debate from the realm of assumptions to undisputed evidence. The assessment should include as many parameters as possible, including clinical as well as laboratory measures of immune functions.

The observation that autologous blood transfusion was associated with a conspicuous incidence of deep vein thrombosis is particularly pertinent in this context. ${ }^{14}$ The observers offered no explanation for this finding which was almost statistically significantly different between the recipients of autologous and homologous blood. I suggest that the incidence of deep vein thrombosis in patients undergoing a range of operations in relation to whether or not they have predeposited autologous blood needs further investigation, either in a separate, or as part of the same suggested randomised controlled trail. If such a difference is confirmed, it would probably be related to the fact that repeated blood donations at short intervals stimulate the bone marrow to compensate by increasing the rate of haemopoiesis, including thrombopoiesis, with the production of increased numbers of large and metabolically active platelets. Coupled with a period of immobility during the operative and postoperative periods, it is not surprising that both factors can lead to enhancement of venous thrombosis. The high incidence of myocardial ischaemic events and cerebrovascular accidents in relation to PAD may be related to the same pathophysiology. The consequences of these complications should also be taken into consideration in the economic appraisal of autologous versus homologous blood transfusion.

$$
\text { Bronglais Hospital, Aberystwyth, SY23 1ER, Wales, UK }
$$

Accepted 26 March 1998

Keywords: blood transfusion 
1 Richards C, Kolins J, Trindale CD. Autologous transfusion-transmitted Yersinia enterocolitica. $\mathcal{F} A M A$ 1992;268:154.

2 Sire JM, Michelet C, Mesnard R, et al. Septic shock due to Yersinia enterocolitica after autologous transfusion. Clin Infect Dis 1993;17:954-5.

3 Goodenough LT, Price TH, Friedman KD, et al. A phase III trial of recombinant human erythropoietin therapy in nonanaemic orthopedic patients subjected to aggressive removal of blood for autologous use: dose, response, subjected to aggressive removal of blood for aut

4 Price TH, Goodnough LT, Vogler WR, et al. The effect of recombinant human erythropoietin on the efficacy of autologous blood donation in patients with low haematocrits: a multicentre randomised, double blind, controlled trial. Transfusion 1996;36:29-36.

5 Etchason J, Petz L, Keller E, et al. The cost effectiveness of preoperative autologous blood donations. N Engl f Med 1995;332:719-24.

6 Duffy G, Tolly K. Cost analysis of autologous blood transfusion, using cell salvage, compared with allogeneic blood transfusion. Transfus Med 1997; 7:189-96.

7 Busch OR, Hop WC, Marquet RL, Jeekel J. Blood transfusion and local tumour recurrence in colorectal cancer. Evidence of noncausal relationship. Ann Surg 1994;220:791-7.
8 Ness PM, Walsh PC, Zahurak M, Baldwin ML, Piantadosi S. Prostate cancer recurrence in radical surgery patients receiving autologous or homologous blood. Transfusion 1992;32:31-6.

9 Ford CD, Gillette JW, Handrahan DL, Koehler CS. Transfusion and second malignancy. Transfusion 1994;37:63-5.

10 Vamakas EC, Moore SB. Confounding and the effect of allogeneic transfusion on survival. Vox Sang 1995;69:142-3.

11 Vamakas EC, Moore SB. Effect of autologous transfusion on length of survival. Vox Sang 1995;69:147-8

12 Pertilla JT, Salo MS, Jalonen JR, Kuttila KT, Viinamaki O, Pulkki KJ. Blood transfusion with autologous and leukocyte-depleted or standard allogeneic red blood cells and the immune response to open heart surgery. Anesth Analg 1994;79:654-60.

13 Tietze $M$, Kluter $H$, Troch $M$, Kirchner $H$. Immune responsiveness in orthopedic surgery patients after transfusion of autologous or allogeneic blood. Transfusion 1995;35:378-83.

14 Howard HL, Rushambuza FG, Martlew VJ, Bolton-Maggs B. Clinical benefits of autologous blood transfusion: an objective assessment. Clin $\mathrm{Lab} \mathrm{Hae}$ matol 1993;15:165-71.

\section{Medical Anniversary}

\section{(Lord) BERKELEY GEORGE ANDREW MOYNIHAN, 2 October 1865}

(Lord) Berkeley George Andrew Moynihan (1865-1936) was born in Malta because his father, a VC, was serving in the Army overseas. When his father died of Malta fever, his mother brought the year-old infant home to Leeds. He qualified in Leeds in 1887 and eventually became its professor of surgery (1909). He was knighted (1912) and raised to the peerage (1929) and became President of the Royal College of Surgeons (1926-32). His drive led to the founding of the Association of Surgeons of Great Britain and of the British Journal of Surgery. He died at his home, Carr Manor, Leeds, on 7 September 1936, six days after the death of his wife. $-D G \mathcal{F a m e s}$ 